\title{
Effect Analysis of Bedding Plane and Fracture Distribution on Crack Propagation Process in Layered Fractured Rock Mass
}

\author{
Long Cheng ${ }^{1}$, Xu Chang ${ }^{1,2}$, Shuren Wang ${ }^{1, *}$, Yunfei Wang ${ }^{1}$ and Minxia Zhang ${ }^{1}$ \\ ${ }^{1}$ International Joint Research Laboratory of Henan Province for Underground Space Development and Disaster Prevention, Henan \\ Polytechnic University, Jiaozuo 454003, China \\ ${ }^{2}$ College of Civil Engineering, Huaqiao University, Xiamen 361021, China
}

Received 4 July 2021; Accepted 21 November 2021

\begin{abstract}
To reveal the effect of bedding plane and fracture distribution on crack propagation process in the layered rock mass, the prefabricated fractured layered rock-like specimens with different bedding plane strengths were prepared, and three-point bending tests were carried out on the specimens in combination with an acoustic emission monitoring system. Based on cohesive element aimming to analyze the path selection of crack propagation at the bedding plane, the influence of prefabricated fracture spacing on the crack propagation in the layered rock mass was investigated by using the numerical simulation method. Results show that the crack propagation path is closely related to the bedding plane strength. There are three fracture patterns during the crack propagation in the layered rock mass, such as crack deflection, crack penetration and coupling of crack deflection and penetration. The specimens with weak to moderate bedding plane have multiple peaks in the load-displacement curves, and the acoustic emission events are more abundant after the peaks accompanied by crack propagation process. The specimens with stronger bedding plane have a single peak in the loaddisplacement curve, showing the brittle fracture characteristics, and the acoustic emission events do not emerge until that close to the peak load. With the increasing of the prefabricated fracture spacing, the fractures generate first through the prefabricated fractures upwards, and the main fracture penetrates the intermediate rock layer within the fracture spacing when the spacing exceeds a certain critical value. The conclusions obtained in this study can provide a basis for predicting the fracture evolution of the layered rock mass.
\end{abstract}

Keywords: Layered rock mass, Three-point bending test, Crack propagation, Bedding plane

\section{Introduction}

The layered rock mass exists widely in nature and it is a complex medium commonly found in the underground engineering [1-2], which is prominently characterized by the presence of a layered structural plane being formed by geological functions, such as mineral deposition, intrusion or directional migration. The deformation and strength of the layered rock mass are obviously anisotropic under the influence of the layered structural plane, while the rock formation also contains a large number of fractures inside due to tectonic and other reasons.

The anisotropic characteristics of the layered rock mass and the discontinuity caused by the structural fissured within the formation can easily induce the instability in the surrounding rock of tunnels and chambers, which poses a significant challenge to the construction and safety of the underground engineering structures. Many accidents related to the layered rock masses have occurred in many countries and regions in the world [3-6]. In recent years, with the continuous development of mining engineering, tunnel engineering, and hydropower engineering, the evolutionary characteristics of the cracks in the layered rock mass have become one of the hotspots and academic frontiers in the rock mechanic field. The geometry and fracture characteristics and its spatial position with the excavation engineering affect the crack propagation process under

*E-mail address: w_sr88@163.com

ISSN: 1791-2377 @ 2021 School of Science, IHU. All rights reserved.

doi:10.25103/jestr.145.11 external loads, which in turn affects the deformation and strength of the layered rock mass.

However, most of the current studies are based on the propagation mechanism of single or multiple fractures in the same lithological rock mass. Most of the researches on crack propagation in the layered rock mass focus on the influence of rock formation properties, bedding plane strength and other factors on the fracture characteristics. In practical engineering, the crack propagation is mainly controlled by the bedding plane and the structural fracture, and it is necessary to conduct in-depth study. Since the bedding plane and structural fracture will directly affect the fracture mode of the layered rock mass, so it is of great significance for practical engineering design and safety construction to reveal the effect of the bedding plane and fracture distribution on the crack propagation process in the layered fractured rock mass.

\section{State of the art}

Many works have been done on the characteristics of cracks propagation in the layered rock mass, and in many sedimentary rocks, penetration or abutmen of fractures have been found on the bedding plane. Gross, et al. had found that the fracture can initiate in the stiffer layers and terminate at the contact with more ductile layers [7-8]. Debecker and Vervoort observed that the load configuration determined whether fractures growed in the layer direction only, or in 
Long Cheng, Xu Chang, Shuren Wang, Yunfei Wang and Minxia Zhang /

Journal of Engineering Science and Technology Review 14 (5) (2021) 90 - 99

both layer and non-layer directions [9]. Hadei and Veiskarami found that there was no deviation observed at the layer interface during the hydraulic crack propagation from the hard layer to the soft layer. However, the possible shear slippage along the layer interface and extending the fracture in the interface would occur when the crack propagated from the soft layer to the hard layer [10]. Douma et al. used manual methods to prepare three-layer rock samples and investigated the fracture behavior under different stress conditions, they found that the mechanical contrast within a layered rock did not always act as a containment barrier and the fractures did not cross the layer interface of the adjacent layer [11]. Heng et al. carried out Brazilian, direct shear and three-point-bending tests on shales of different shapes and bedding plane orientations, they figured out that a complex fracture geometry with tortuous propagation paths was usually generated by the bedding cracking deviation towards the bedding-parallel orientation [12-14].

Some studies have also been carried out on the fractured rock mass. For examples, Chang et al. conducted compression tests on single-filled fractured rock mass, they found there existed a critical infill strength which controled crack patterns for a given flaw inclination angle and the stiffness of the specimen increased with the increasing of the filling strength. In addition, the fracture extension and fracture coalescence in the layered rock mass and interaction with bedding planes were discussed, and the behavior of the prefabricated fractures on the induction of fracture extension in the layered rock mass was also analyzed [15-19]. Yang et al. carried out uniaxial compression tests on sandstones containing non-parallel double fractures and parallel triple fractures to investigate the effects of prefabricated fracture geometry conditions on the fracture initiation, extension, association properties and on the mechanical properties of the sandstone [20-22]. Luo et al. made the prefabricated joint specimens with granite and conducted uniaxial compression tests on the joint specimens using anchors with different inclination angles. They found that the stress, anchoring force, bolt strain and crack evolution of the jointed specimens had a strong intrinsic correlation [23]. Lei et al. conducted an experimental and numerical study of sandstones containing two gypsum-filled parallel fractures, they observed 10 types of the fractures and identified four patterns of the fracture coalescence [24-26].

The previous studies shows that most of these on the layered rock mass have focused on the influence of the nature of the rock formation and the cementation of the bedding plane on the fracture characteristics, and the influence of the prefabricated fractures on the crack propagation has been mostly focused on the homogeneous rock mass. However, the structural effect of the prefabricated fractures and bedding planes in the layered rock mass has been less reported. Therefore, this study investigated the effect of the bedding plane strength on the crack propagation in the layered rock mass by producing rock specimens with different bedding plane strengths of the prefabricated fractured layered rock mass and performing three-point bending tests in combination with the acoustic emission (AE) techniques. The numerical model of complex crack paths in the layered rock mass was also established by inserting the cohesive element into the solid elements with self-written software, focusing on the selection of the crack propagation paths at the bedding plane and exploring the effect of the prefabricated fracture spacing on the crack propagation in the layered rock mass.
The rest of this study is organized as follows. Section 3 introduces the preparation, test scheme, the numerical simulation model and research method of the samples. Section 4 gives the results and discussion, and finally, the conclusions are summarized in Section 5.

\section{Methodology}

\subsection{Physical modelling experiment}

The material ratio of the specimens used in the test was cement: quartz sand: water $=1: 1: 0.6$ (mass ratio), and the mechanical parameters of the similar material were listed in Table 1. The cement, quartz sand and water were mixed according to the ratio, stirred and poured into the prepared mold. Due to the large water-cement ratio, the cement mortar had a good flowability and a few bubbles could emerge from the interior with a slight vibration. After a few hours of resting, the surface was dried up with absorbent paper and the upper layer was poured, with an appropriate amount of ink being added to the second layer to differentiate the rock layers. The pouring process and the finished specimens are shown in Fig. 1.

Table 1. Properties of rock-like materials.

\begin{tabular}{c|c|c}
\hline Materials & Shale & Rock-like \\
\hline Density $\left(\mathrm{g} \cdot \mathrm{cm}^{-3}\right)$ & $2.0-2.70$ & 2.07 \\
\hline Compressive strength $(\mathrm{MPa})$ & $10-100$ & 34.42 \\
\hline Tensile strength $(\mathrm{MPa})$ & $2-10$ & 3.3 \\
\hline Young's modulus $(\mathrm{GPa})$ & $10-80$ & 9.87 \\
\hline Cohesion $(\mathrm{MPa})$ & $8-40$ & 8.65 \\
\hline Friction angle $\left({ }^{\circ}\right)$ & $15-34$ & 33.9 \\
\hline Possion's ratio $(\%)$ & $0.19-0.40$ & 0.19 \\
\hline
\end{tabular}

The three-point bending loading equipment was a $50 \mathrm{kN}$ universal testing machine, and the loading control method was displacement control, with a displacement control rate of $0.02 \mathrm{~mm} / \mathrm{min}$. During the loading test, the information was monitored synchronously with the AE system. The loading mode schematic diagram is shown in Fig. 2.
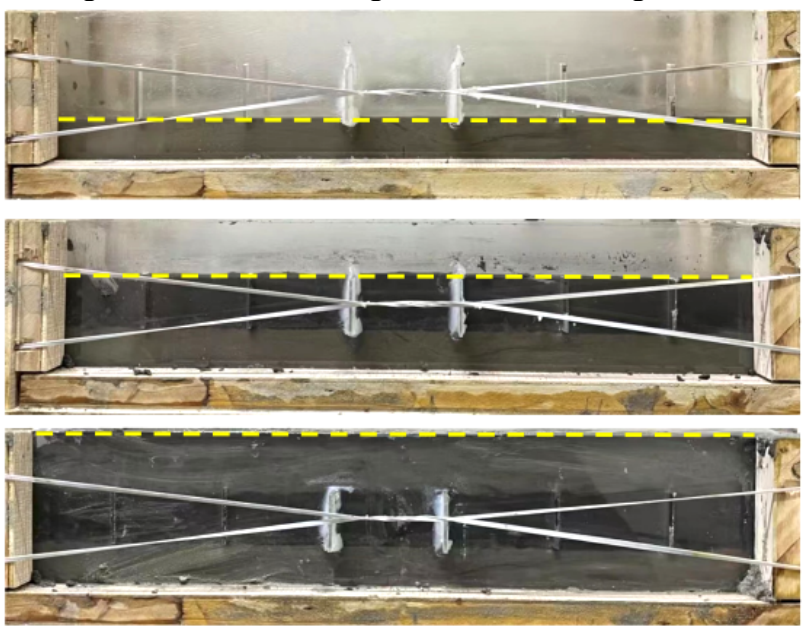

(a) Steped pouring in layers.

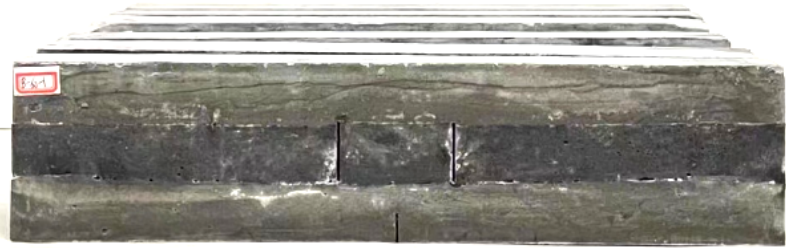

(b) Part of completed specimen.

Fig. 1. Specimen preparation. 
Long Cheng, Xu Chang, Shuren Wang, Yunfei Wang and Minxia Zhang /

Journal of Engineering Science and Technology Review 14 (5) (2021) 90 - 99

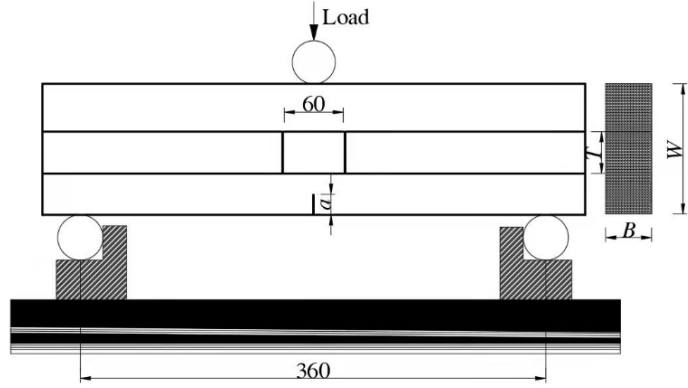

Fig. 2. Specimen size and loading method.

\subsection{Numerical simulation method}

\subsubsection{Selecting constitutive model}

As shown in Fig. 3, the bilinear intrinsic model was used to establish a numerical model of the layered rock mass with the horizontal coordinates indicating displacement and the vertical coordinates indicating stress. The slope of this segment was the stiffness of the cohesive element. After the damage initiation point was the linearly reduced softening phase, and the area included under the curve of this segment was the energy release rate of the material at fracture.

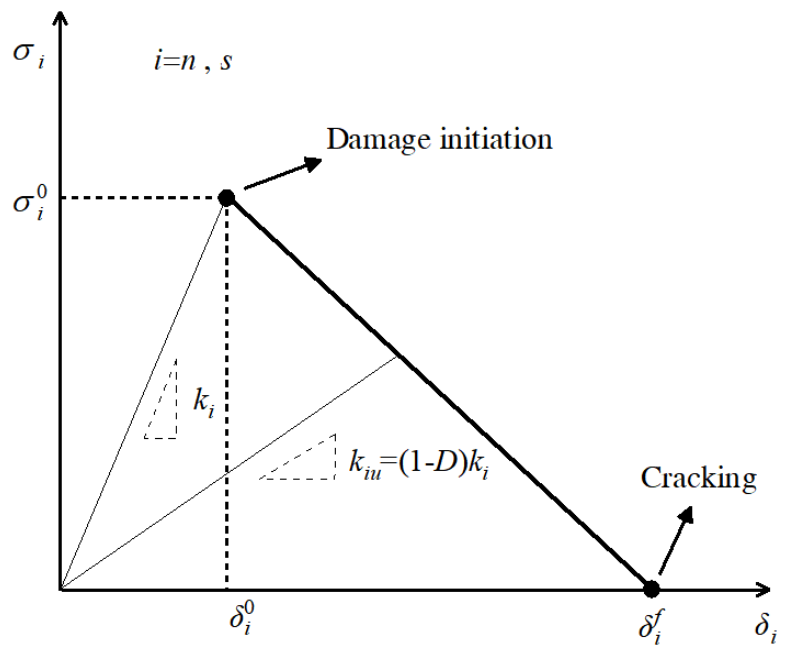

Fig. 3. Separation pattern of the cohesive element.

The stiffness of the cohesive element can be explained by the elasticity as :

$\delta=\frac{P L}{A E}$

where, $L$ denotes the length, $E$ denotes the elastic stiffness, $A$ is the initial cross-sectional area and $P$ is the load, which can be rewritten as:

$\delta=\frac{S}{K}$

where, $S=P / A$ is the nominal stress, and $K=E / L$ is the material stiffness.

Then, $K$ can be written as:

$K=\frac{E}{L}=\frac{E / L}{1}=\frac{E / L}{L^{\prime}}$

where, $L$ denotes the geometric thickness, $L^{\prime}$ denotes the actual thickness of the cohesive interface, $E / L$ denotes the stiffness of the cohesive interface, and $(E / L) / L^{\prime}$ is the actual stiffness of the cohesive interface.

The traction separation law in ABAQUS includes six initial damage criteria, of which the following are generally used to model the composite delamination: Quade damage, Maxe damage, Quads damage and Maxs damage. Maxpe damage and Maxps damage are generally used to model discontinuities. In this study, the maximum nominal stress criterion, Maxs damage, was used, which is defined as the damage that occurs when the ratio of any one nominal stress is equal to 1 .

$$
\max \left\{\frac{\sigma_{n}}{\sigma_{n}^{0}}, \frac{\sigma_{s}}{\sigma_{s}^{0}}, \frac{\sigma_{t}}{\sigma_{t}^{0}}\right\}=1
$$

\subsubsection{Building cohesive element model}

The geometrical structures of the specimeny shown in Fig. 4 was modelled by means of a cohesive zone and the wedge was selected as the element shape, which was then meshed by means of a sweep.

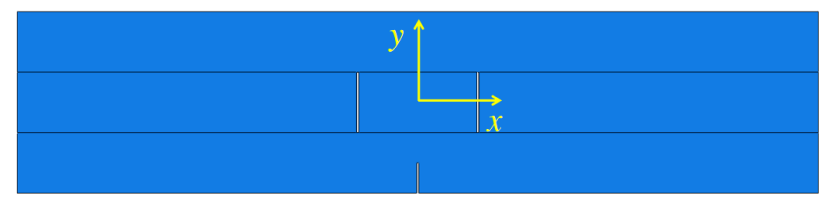

Fig. 4. Geometrical structures of the specimen.

As shown in Fig. 5, the cohesive element was inserted between the solid element through the software interface. To improve the efficiency of the calculation, the specimen model was taken to a unit with the thickness of $2 \mathrm{~mm}$, considering the assumption of plane stress.

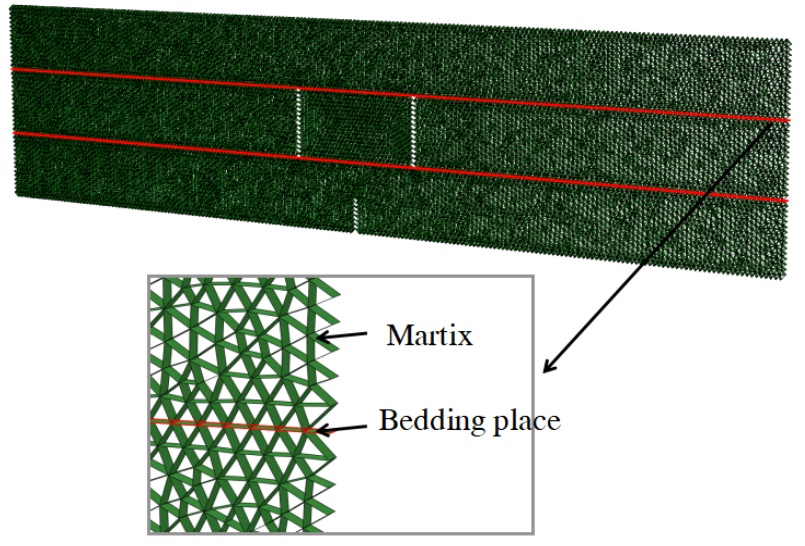

Fig. 5. The numerical model for the test.

\subsubsection{Model validation analysis}

The parameters used for the cohesive elements of the bedding planes and rock matrix are impossible to be determined through experiments, it is necessary to calibrate the microscopic parameters of cohesive in ABAQUS based on the macroscopic mechanical properties of the specimens measured in the three-point bending test [27].

In this study, the peak load and the fracture pattern were used as the calibration indicators. These computational parameters were adjusted repeatedly and the corresponding numerical results were compared with the experimental results until the simulation results matched the experimental results. So, the calibrated cohesive element parameters are listed in Table 2.

Table 2. Mechanical parameters of the numerical model. 
Long Cheng, Xu Chang, Shuren Wang, Yunfei Wang and Minxia Zhang /

Journal of Engineering Science and Technology Review 14 (5) (2021) 90 - 99

\begin{tabular}{c|c|c|c|c|c}
\hline \multirow{2}{*}{ Name } & Solid element & \multicolumn{4}{|c}{ Cohesive element } \\
\cline { 2 - 6 } & $\begin{array}{c}\text { Rock } \\
\text { materials }\end{array}$ & Martix & I1 & I2 & I3 \\
\hline Density $\left(\mathrm{g} \cdot \mathrm{cm}^{-3}\right)$ & 2.07 & & & & \\
\hline $\begin{array}{c}\text { Young's modulus } \\
(\mathrm{GPa})\end{array}$ & 9.87 & & & & \\
\hline $\begin{array}{c}\text { Possion's ratio } \\
(\%)\end{array}$ & 0.19 & 9870 & 1200 & 1200 & 1200 \\
\hline $\begin{array}{c}\text { Normal stiffness } \\
(\mathrm{MPa} / \mathrm{mm})\end{array}$ & & 4147 & 504.2 & 504.2 & 504.2 \\
\hline $\begin{array}{c}\text { Shear stiffness } \\
(\mathrm{MPa} / \mathrm{mm})\end{array}$ & & 10 & 1.5 & 10.2 & 15 \\
\hline $\begin{array}{c}\text { Tensile strength } \\
(\mathrm{MPa})\end{array}$ & & 0.5 & 3.4 & 5 \\
\hline $\begin{array}{c}\text { Shear strength } \\
(\mathrm{MPa})\end{array}$ & & & &
\end{tabular}

to reach the second bedding plane. The bedding plane then debonded across the middle and finally the crack penetrated the upper rock layer and the specimen was damaged. Fig. 7(c) shows the failure pattern of Group F specimens (interlayer pouring interval of $1 \mathrm{~h}$ ). The specimens in Group $\mathrm{F}$ have a shorter pouring interval and strong inter-layer strength, and the cracks penetrate directly through the upper two rock layers after starting cracks from the prefabricated cut, and no crack deflection occurs. Fig. 7(b) shows the failure pattern of the specimen of Group B (inter-layer pouring interval of $3.5 \mathrm{~h}$ ). The bedding plane strength of the Group B specimen is between Groups C and F. The crack starts from the prefabricated cut, reaches the first bedding plane and randomly deflects to the left. The deflection length does not reach the prefabricated fracture of the second layer before penetration occurs, and after reaching the second bedding plane, it deflects to the left again to the prefabricated fracture and penetrates the upper rock layer.

each model obtained from the simulation and the test results, which shows that the peak load of the specimens increases with the increase of the bedding plane strength, and these two results are in good agreement. Fig. 6(b) shows the experimental and simulated crack propagation paths are also in general agreement.

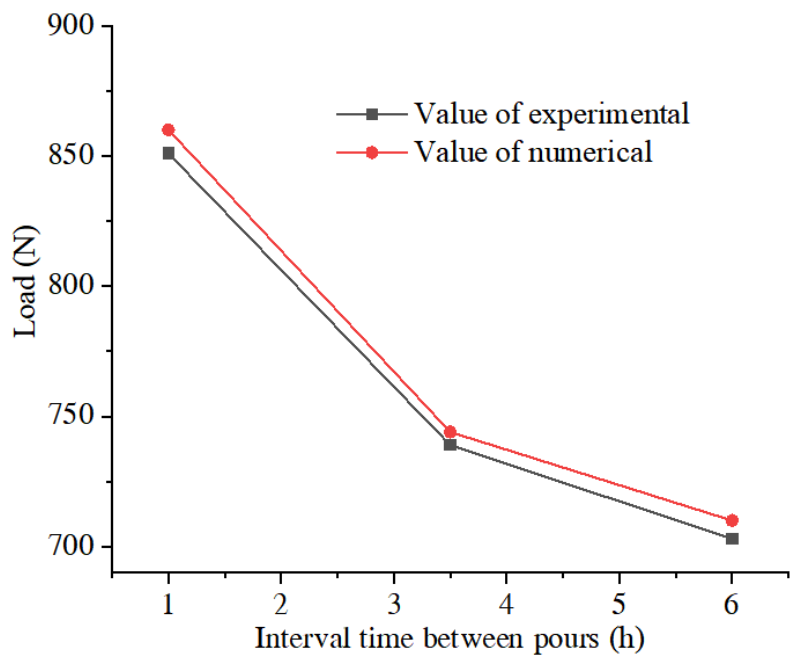

(a) Correlation curves of the peak load.
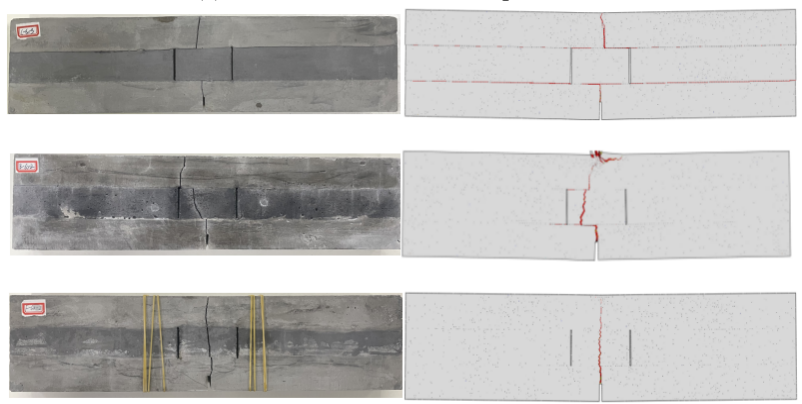

(b) Comparison of the failure modes.

Fig. 6. Comparison of the simulation and experiment results.

\section{Results and discussion}

\subsection{Analysis of failure pattren}

It can be seen from Fig. 7, the three sets of specimens with different bedding plane strengths show different failure pattrens. Fig. 7(a) shows the fracture path of the specimen in group $\mathrm{C}$ (inter-layer pouring interval of $6 \mathrm{~h}$ ). Due to the relatively long pouring interval and the weak inter-layer strength, the cracks start cracking from the prefabricated incision and extend randomly towards the ends along the bedding plane after reaching the first bedding plane. After reaching the location of the prefabricated fracture in the second layer and penetrating along the prefabricated fracture

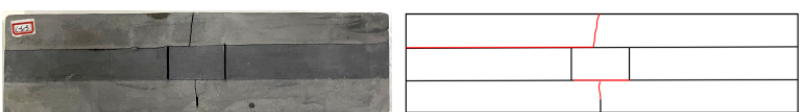

(a) Group C

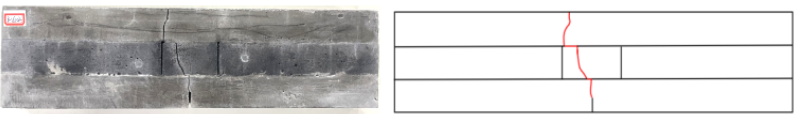

(b) Group B

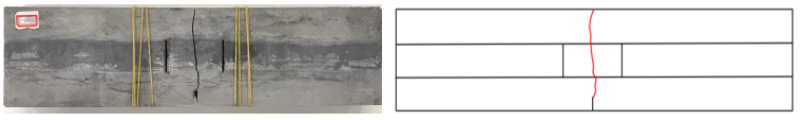

(c) Group F

Fig. 7. Crack propagation paths in layered rock specimens.

4.2 Mechanical properties and fracture energy analysis Fig. 8 shows the typical load-displacement curves of the three groups of the specimens. The different bedding plane strengths directly determine the deformation and strength characteristics of the three groups of specimens. When the bedding plane strength is weak (Group C, Group B), the load-displacement curve shows a phased, multi-peak feature. When the bedding plane strength is strong (Group F), the force-displacement curve shows a single peak, and the load reaches its peak and then falls to zero rapidly, showing brittle failure. With the increasing of the bedding plane strength, the peak load increases at the time of the specimens failure.

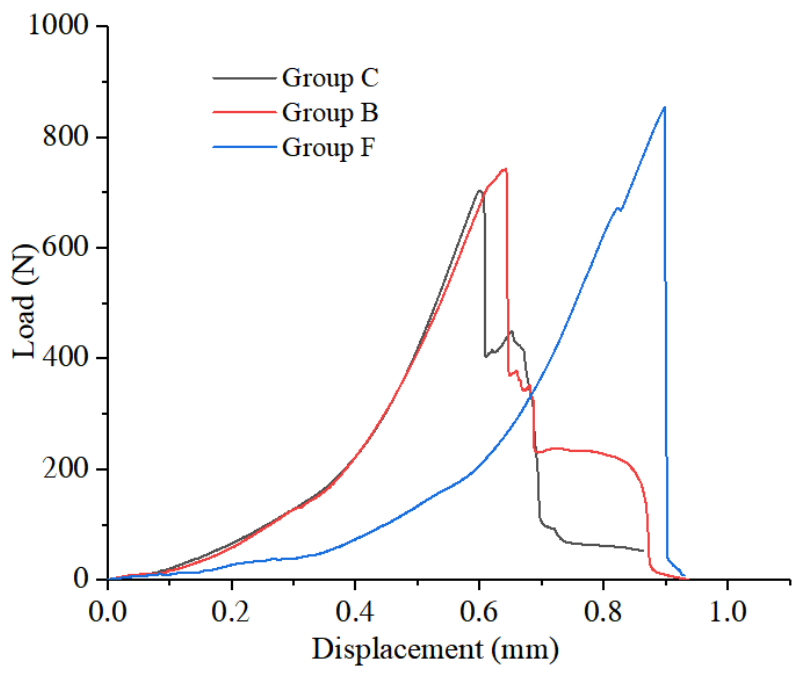

Fig. 8. Typical load-displacement curves of three groups of specimens. 
Long Cheng, Xu Chang, Shuren Wang, Yunfei Wang and Minxia Zhang /

Journal of Engineering Science and Technology Review 14 (5) (2021) 90 - 99

To characterize the process of the crack evolution, which is further illustrated on the basis of the load-displacement curves of the specimens, the process of the crack evolution for the specimens in Group C (interval of $6 \mathrm{~h}$ between pours) is shown in Fig. 9, with the characteristic points marked on the curves with the following definition.

Point A - Adjustment completion point during loading of the specimen; Point B - The sprouting of primary cracks in the first layer, i.e. the formation of macroscopic cracks; Point C - Formation of the main crack in the first layer; Point D - The emergence and propagation of horizontal cracks in the first bedding plane; Point E - horizontal crack in the first bedding plane across the fracture spacing to the second bedding plane; Point F - penetration of the main crack in the third layer.

The rising and plateau stages in the curve are represented by I, II and III. In stage I - section AB, the cracks in the first rock layer start to sprout when they reach about half of the peak load, and when the load reaches the peak point $B$, the macroscopic cracks can be clearly distinguished during the test. In stage II - section CD, the cracks extend inside the first layer to reach the second prefabricated fracture. In stage III - section EF, the cracks reach the second bedding plane and extend towards the upper rock layer until the specimen is destabilization failure.

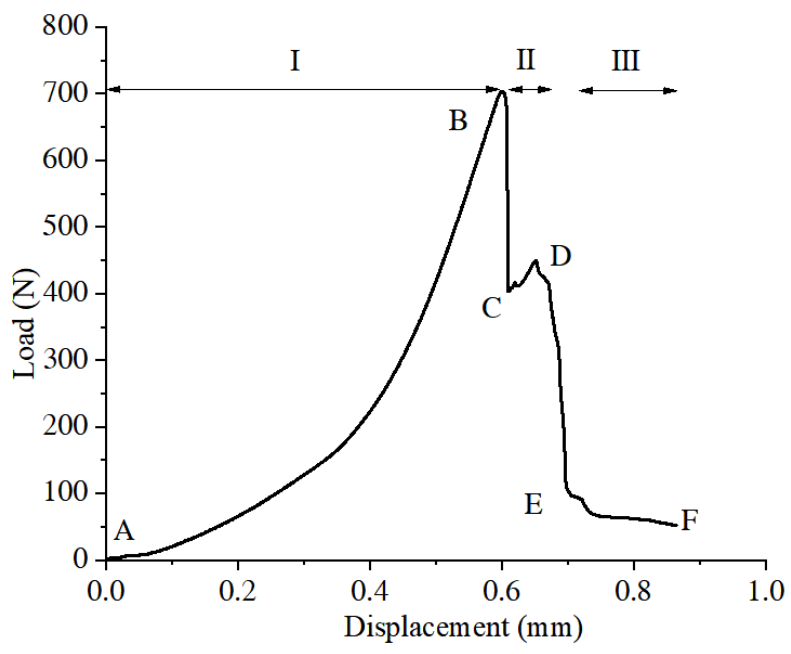

(a) Load-displacement curves.
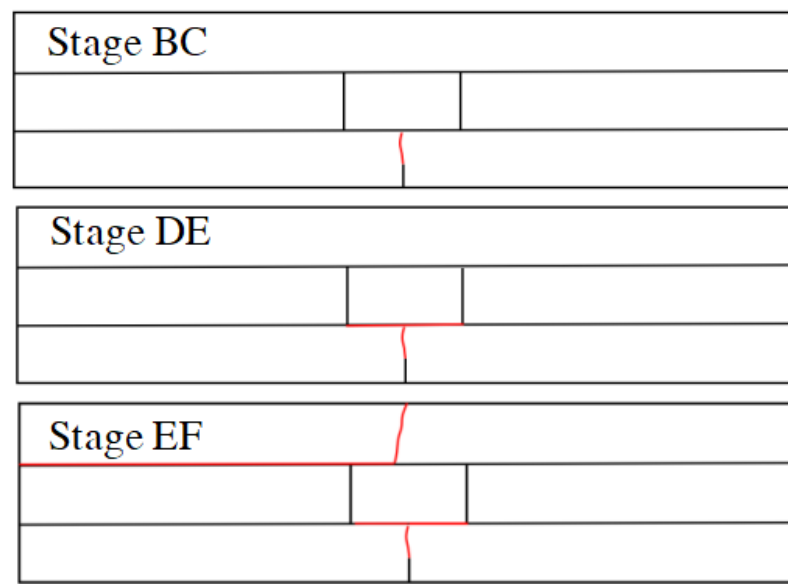

(b) Crack propagation path.

Fig. 9. The load-displacement curve and crack propagation path for Group C specimens.

The crack evolution of the specimens in Group B (interval of $3.5 \mathrm{~h}$ between pours) is shown in Fig. 10, with the characteristic points marked on the curves having the following definitions.
Point A - Adjustment completion point during loading of the specimen; Point B - The sprouting of primary cracks in the first layer, namely the formation of macroscopic cracks; Point C - Formation of the main crack in the first layer; Point D - The emergence and propagation of horizontal cracks in the first bedding plane; Point E - Failure of the horizontal crack in the first bedding plane to reach the prefabricated fracture and penetrate the intervening rock layer to reach the second bedding plane; Point F - Extension of the crack to the left in the second bedding plane; Point $\mathrm{G}$ Crack reaches the prefabricated fracture and extends into the upper layer with the main fracture in the third layer penetrating.

In stage I - section $A B$, the cracks in the first rock layer start to sprout when they reach about half of the peak load, and when the load reaches the peak point $\mathrm{B}$, the macroscopic cracks can be clearly distinguished during the test. In stage II - section $\mathrm{CD}$, the cracks develop randomly to the left in the first bedding plane within the two prefabricated fractures. In stage III - section EF, the cracks penetrate the middle rock layer to reach the second bedding plane, expanding to the left and after the crack reaches the location from which the prefabricated fracture emerges, it expands into the upper rock mass, point $\mathrm{G}$, where the third main crack penetrates.

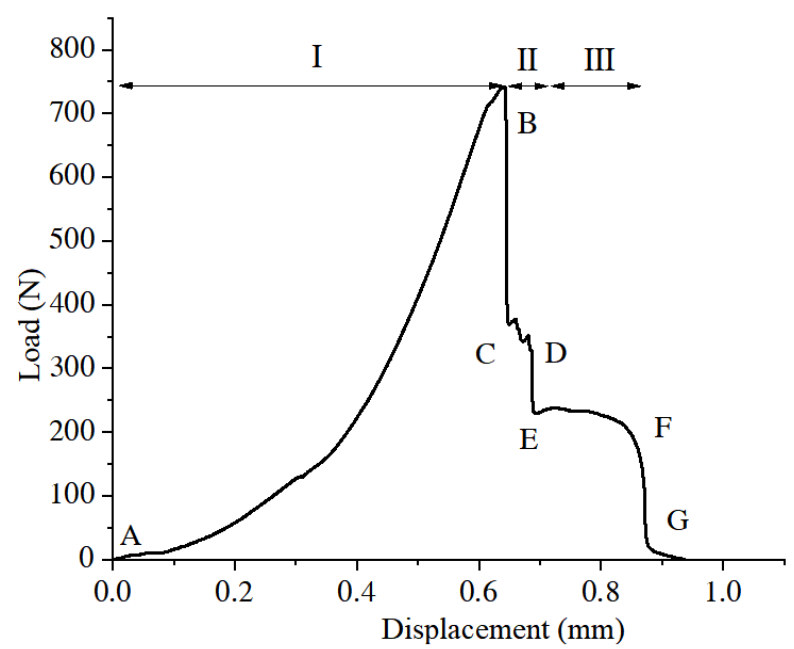

(a) Load-displacement curves

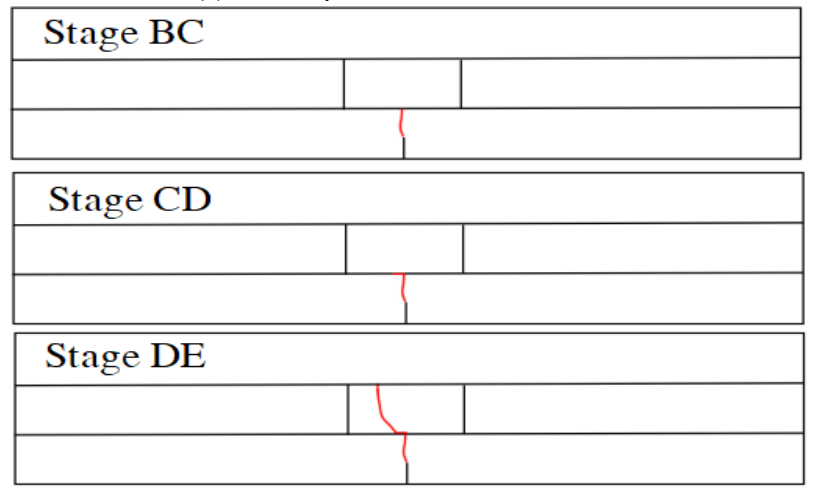

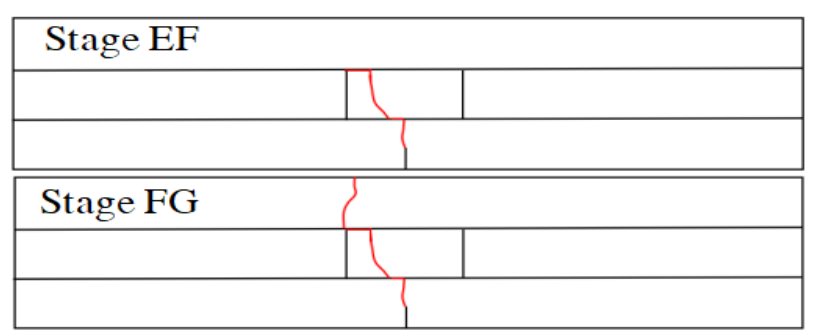

(b) Crack propagation path.

Fig. 10. The load-displacement curve and crack propagation path for Group B specimens. 
The crack evolution of the specimens in Group $\mathrm{F}$ (interval of 1 hour between pours) is shown in Fig.11, with the characteristic points marked on the curves having the following definitions.

Point A - Adjustment completion point during loading of the specimen; Point B - main crack sprouting; Point C main crack penetrates all the rock layer and forms a macro fracture.

As the bedding plane strength of the Group F specimen is higher, the specimen failure is sudden destabilization and only one macroscopic crack appears, so there is only one rising stage I in the Group F specimen.

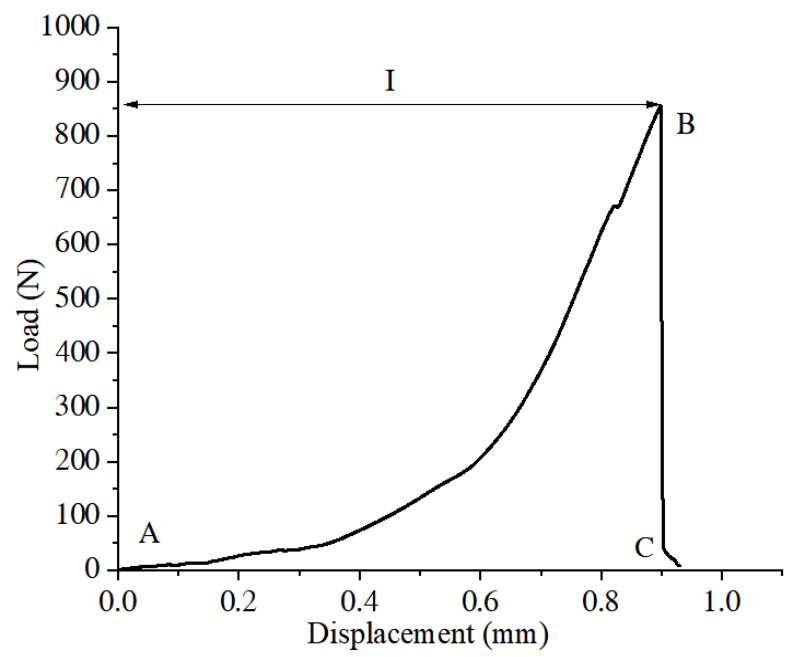

(a) Load-displacement curves.

\begin{tabular}{|c|}
\hline Stage BC \\
\hline \\
\hline
\end{tabular}

(b) Crack propagation path.

Fig. 11. The load-displacement curve and crack propagation path for Group F specimens.

Fracture energy measures the amount of energy required to break a material in terms of energy, and which is an important parameter for expressing the fracture properties of a material. The fracture energy of rock materials is usually determined using the three-point bending test. Based on the definition of fracture energy and the energy principle, it is assumed that all the work done by the external load in the three-point bending test is used to form a new fracture surface. The fracture energy is solved based on the loaddisplacement curve at the loading point recorded in the test.

$\mathrm{G}_{f}=\frac{W+m g \delta}{A}$

$W=\int_{0}^{\delta} P d \delta$

$A=B \times(H-a)$

where, $G_{f}$ is the fracture energy. $W$ is the work done by the external load. $m$ is the mass of the specimen. $g$ is the acceleration of gravity. $\delta$ is the fracture damage displacement of the specimen. $P$ is the load. $A$ is the area of the fracture surface. $B$ is the thickness of the specimen. $H$ is the height of the specimen and a represents the length of the prefabricated fracture.
The work done by the external load, $W$ is the shaded area below the load-displacement curve and can be obtained by integrating the load-displacement curve with Eq. (6). $m g \delta$ is the work done by the specimen's self-weight during the fracture process. The results of the fracture energy calculations for the specimens are shown in Fig. 12.

As the bedding plane strength of the specimens in Group $\mathrm{B}$ (interval of $3.5 \mathrm{~h}$ between pours) is higher than that of Group $\mathrm{C}$ (interval of $6 \mathrm{~h}$ between pours), the resistance to crack propagation is relatively higher. So, the fracture energy consumed during the fracture damage of the specimens in group $\mathrm{C}$ is larger than that of group $\mathrm{B}$. However, the energy released during the fracture of the specimens in group $\mathrm{F}$ (interval of $1 \mathrm{~h}$ between pours) suddenly decreases, where the bedding plane strength is high enough, mainly because the cracks do not extend along the layer and break directly through the layers, so that the specimens require less external work to break.

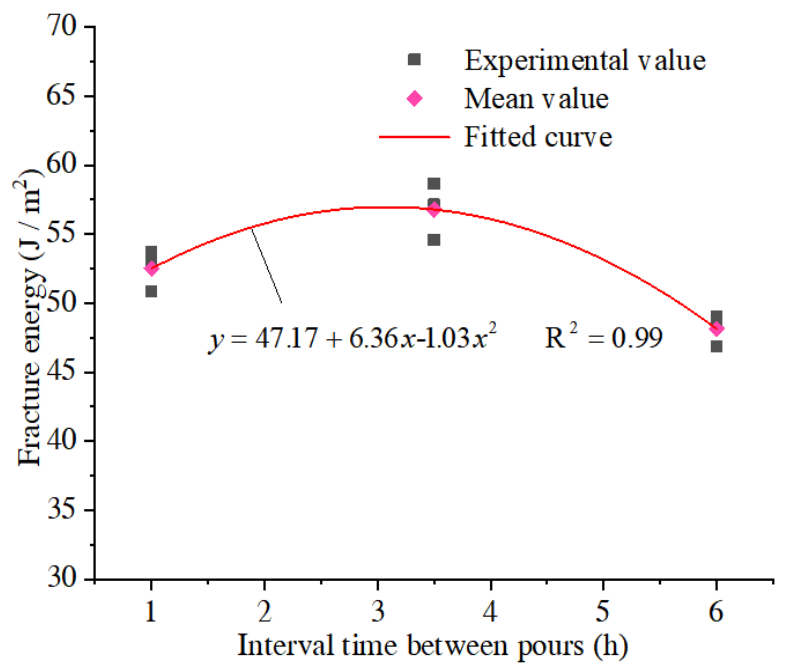

Fig. 12. Fracture energy as a function of interval time between pours.

\subsection{Analysis of acoustic emission characteristics}

When a material is deformed or ruptured by an external load, the internal representative elemental volume release energy and the resulting strain-energy is released outwards in the form of elastic-wave, known as AE. AE is mainly based on the $\mathrm{AE}$ characteristic parameters to reflect the stability of material deformation or rupture. The AE ringing count is the number of oscillations per unit time that exceeds the threshold value.

Fig. 13 shows the relationship between the AE ringing counts and loading with time for the three specimen groups. These specimens show similar AE characteristics at the beginning of the loading. As the load increases, the layered structure and micropores inside the specimens are gradually compressed, the AE activity is calmer and the strain-energy inside the layered rock is accumulated. As the load continues to increase near the first peak load, the specimens with lower bedding plane strength (Group C) are cracked from the prefabricated fracture through to the first bedding plane to form macroscopic cracks, the strain-energy accumulated inside the rock is released, the AE activity is more active and the $\mathrm{AE}$ ringing signal response is relatively strong. Along with the crack propagation along the bedding plane, the $\mathrm{AE}$ event is obvious. As the load continues to increase and reaches a second peak, the load then falls off a cliff. At this time the first bedding plane is completely debonded, but there is still a certain residual strength with a certain loadcarrying capacity. So, the AE activity after the peak still has 
a partial response, and the cumulative $\mathrm{AE}$ ringing count shows a certain growth trend. The cracks reach the upper rock layer, and finally the specimen gradually loses its loadcarrying capacity (Fig. 13(a)).

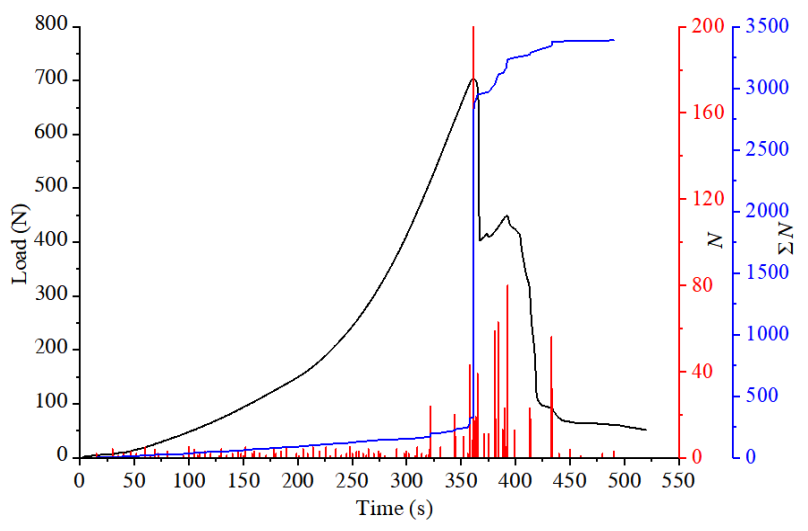

(a) Group C.

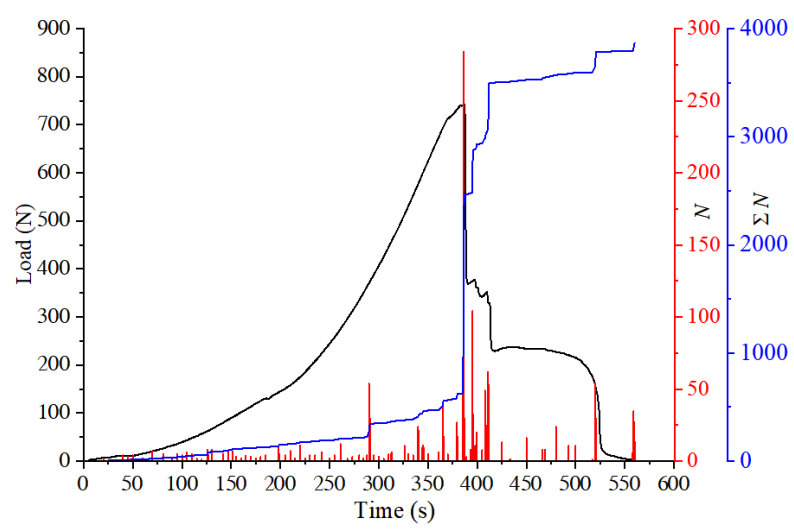

(b) Group B.

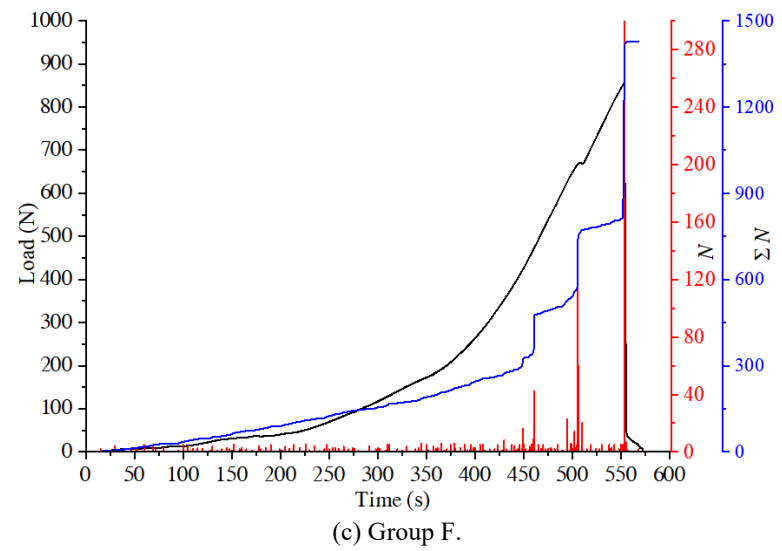

Fig. 13. The monitored $\mathrm{AE}$ counts with time.

When the bedding plane strength is at a moderate level (Group B), after the load reaches the first peak load, accompanied by the crack propagation along the first bedding plane, AE events are more obvious. When the fracture penetrates the middle rock layer to reach the second bedding plane, more AE events are generated, and finally the fracture passes the upper rock layer (Fig. 13(b)).

When the bedding plane strength is strong (Group F), after the load reaches the first peak load, the load cliff falls to zero and loses its load carrying capacity, and the specimen is brittle failure. At this time, the AE activity basically no responds, and the cumulative AE ringing count basically no increases (Fig. 13(c)).

\subsection{Analysis of the crack propagation at bedding plane}

As shown in Fig. 14, the first and second layer rock are divided into separate prefabricated fracture regions. The strength condition can be simplified as follows: the upper surface of the second layer rock is subjected to a uniform load, the lower rock mass has fixed displacement in the ydirection on both sides and is subjected to a uniform tensile load in the $x$-direction. This simplified model is used to focus on the crack propagation at bedding plane.

As the bedding plane strength increases, the three typical failure patterns can be obtained. When the bedding plane strength is weak enough, debonding of the bedding plane occurs and the crack develops symmetrically along the bedding plane towards the ends. If the bedding plane strength is strong enough, the crack will penetrate the bedding plane and continue to propagate in the upper rock layer without any bedding plane debonding. If the bedding plane strength approaches a certain critical value, the crack will be deflected. The bedding plane debonding coexists with the crack penetration. For discussion purposes, the evolution of the normal stress and shear stress on the bedding plane is analyzed.

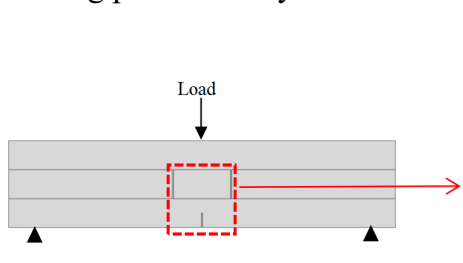

(a) Layered rock mass model.

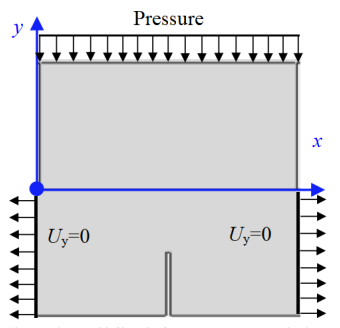

(b) Simplified fracture model.

Fig. 14. The mechanical model and its simplified fracture model.

Fig. 15 shows the numerical crack propagation process at weak bedding plane strength ( $\sigma 0 \mathrm{n}=0.5 \mathrm{MPa}$ ). Depending on the propagation direction, the whole process can be divided into two stages. In the first stage (Fig. 15(a): Disp. $0.4 \mathrm{~mm}$ ), the crack extends vertically along the beding plane direction. As the crack approaches the bedding plane, the cracking of the bedding plane starts at its mid-point and then propagates symmetrically along the bedding plane (Fig. 15(a): displacement increases from 0.6 to 0.7 ). The crack appears to be prevented or blunted at the bedding plane and becomes more open to adapt the increasing tensile load. The evolution of the normalized tensile stresses and normalized shear stresses along the bedding plane are shown in Figs. 15(b) and 15(c). The tensile stresses and shear stresses increase as the crack propagates towards the bedding plane. When the distance between the crack and the bedding plane decreases to a certain value, the crack in starts from the midpoint of the bedding plane and propagates along the bedding plane. During the propagation process, the peak shear stress gradually increases. The tensile stress continues to increase along the bedding plane until the bedding plane is completely disconnected near the end of it. During crack propagatiom, the maximum tensile stress does not exceed the tensile strength of the upper layer rock, so the crack cannot penetrate the bedding plane.

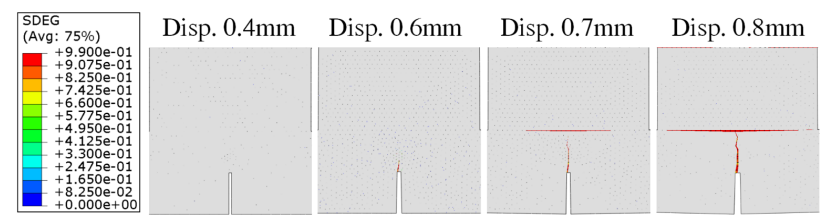

(a) Fracture process, SDEG used to describe the damage variable. 


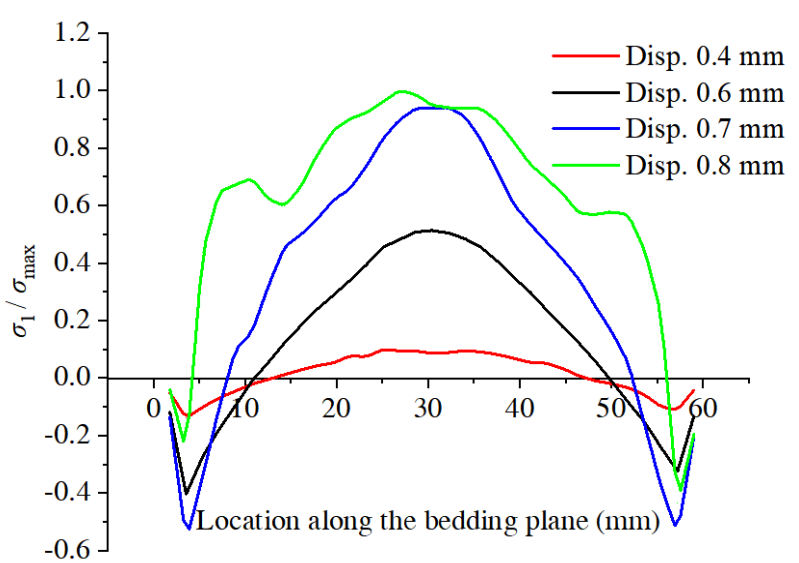

(b) Normalized tensile stress along the bedding plane.

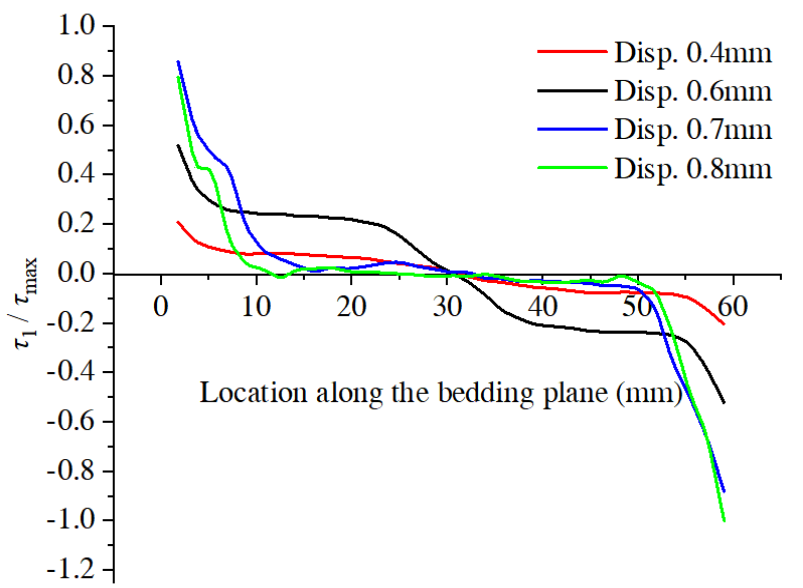

(c) Normalized shear stress along the bedding plane.

Fig. 15. The tensile stress of bedding plane with $0.5 \mathrm{MPa}$.

Fig. 16 shows the numerical crack propagation process at bedding plane mid-strength $(\sigma 0 \mathrm{n}=3.4 \mathrm{MPa})$. The whole process can be divided into three stages. In the first stage, the crack penetrates to the bedding plane (Fig. 16(a): Disp. $0.4 \mathrm{~mm}$ ). After the crack approaches the bedding plane, the debonding occurs and spreads symmetrically towards both ends (Fig. 16(a): Disp. $0.6 \mathrm{~mm}$ ). As the tensile load is further increased, the crack randomly penetrates the bedding plane on the right side (Fig. 16(a): Disp. $0.8 \mathrm{~mm}$ ). The crack then propagates in the upper bedding plane (Fig. 16(a): Disp. 1 $\mathrm{mm})$. It is worth noting that once the crack penetrates the bedding plane, the propagation along the bedding plane stops. The evolution of the normalized tensile stresses and normalized shear stresses along the bedding plane are shown in Figs. 16(b) and 16(c). It can be seen that both tensile and shear stresses increase as the crack propagates towards the bedding plane, which is similar to the case where the bedding plane strength is weak. However, as the crack propagates, the tensile stresses along the bedding plane exceed the tensile strength of the rock mass. As a result, the shear stress and tensile stress along the bedding plane are reduced to lower levels.

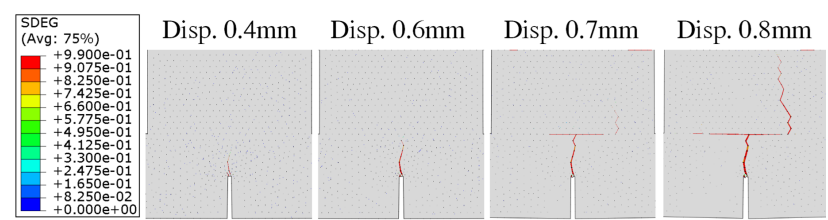

(a) Fracture process, SDEG used to describe the damage variable.

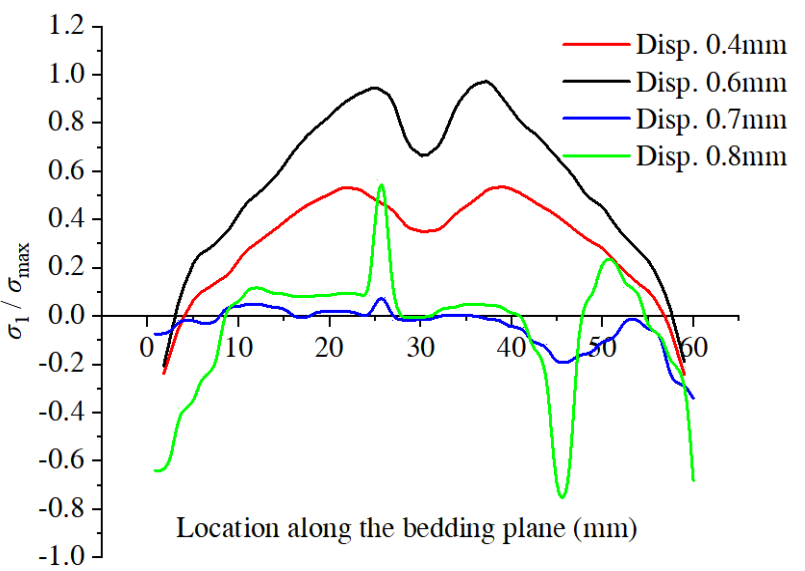

(b) Normalized tensile stress along the bedding plane.

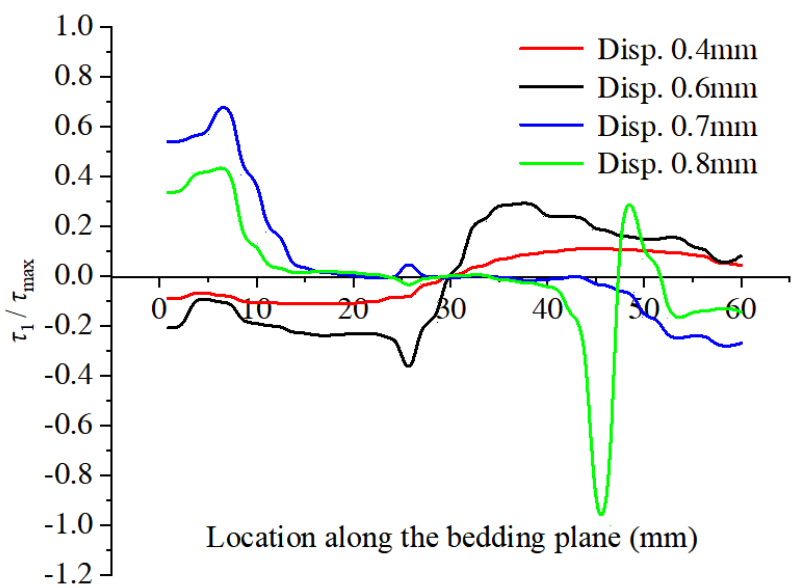

(c) Normalized shear stress along the bedding plane.

Fig. 16. The tensile stress of bedding plane with $3.4 \mathrm{MPa}$.

Fig. 17 shows the crack propagation process at stronger bedding plane strength ( $\sigma 0 \mathrm{n}=5 \mathrm{MPa})$. In this case, the crack passes directly through the bedding plane without any debonding. The evolution of the normalized tensile stresses and normalized shear stresses along the bedding plane is shown in Figs, 17 (b) and 17(c). The tensile stress increases as the crack approaches the bedding plane and suddenly decrease with penetrating the bedding plane. As the crack propagation towards the bedding plane, the shear stress increases but not exceed the bedding plane strength.

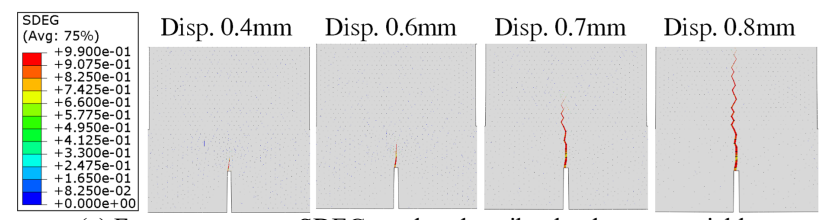

(a) Fracture process, SDEG used to describe the damage variable

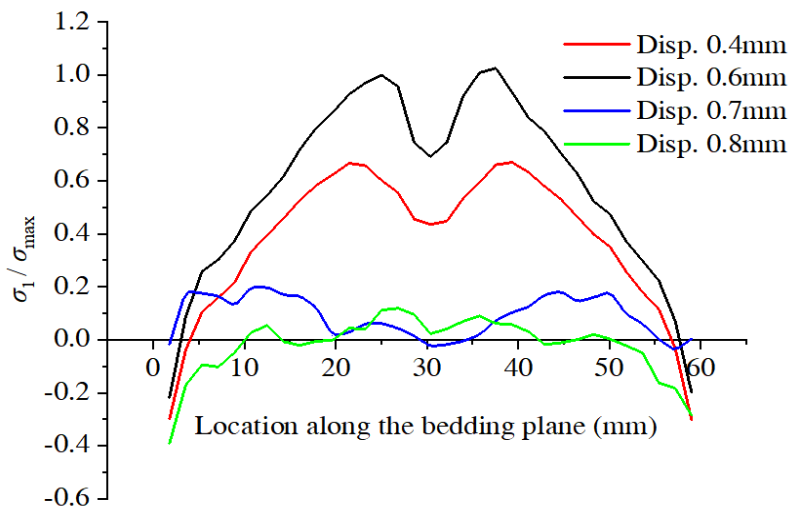

(b) Normalized tensile stress along the bedding plane. 


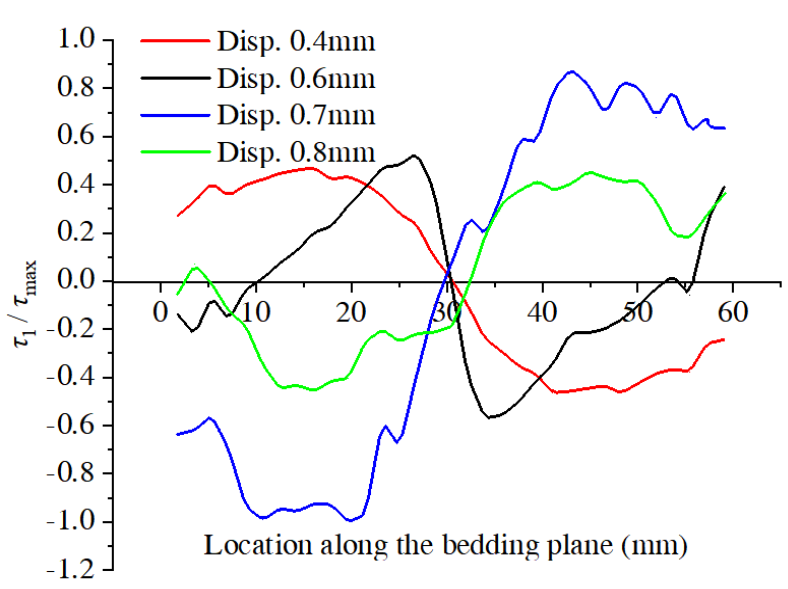

(c) Normalized shear stress along the bedding plane

Fig. 17. The tensile stress of bedding plane with $5 \mathrm{MPa}$.

\subsection{Fracture spacing effect on fracture evolution}

Due to the material strength, when expanding the prefabricated fracture spacing, cracks will always penetrate directly from the intermediate layer rock, despite the weak bedding plane. In order to investigate the effect of prefabricated fracture spacing on crack propagation in layered rock mass, this section increases the tensile strength of the material by 10 times and keeping other parameters constant, and sets up layered rock mass specimens with six different fracture spacings to analyze the effect of prefabricated fracture spacing on the process of crack evolution in layered rock masses.

The failure pattern of specimens with different fracture spacing are given in Fig. 18. It can be seen from Fig. 18(a), where the bedding plane tensile strength is $\sigma 0 \mathrm{n}=0.5 \mathrm{MPa}$, that as the fracture spacing increases, the cracks all propagate along the bedding plane, and reach the upper rock layers through the prefabricated fractures, which caused by the weak bedding plane strength. The bedding plane tensile strengths in Figs. 18(b) to 18 (c) are is $\sigma 0 \mathrm{n}=1 \mathrm{MPa}, 2 \mathrm{MPa}, 4$ $\mathrm{MPa}$ and $10 \mathrm{MPa}$, respectively. As the bedding plane strength increases, the ability of the cracks penetrating through the mid-layer gradually increases.

When $\sigma 0 \mathrm{n}=1 \mathrm{MPa}$, cracks penetrate in the mid-layer of specimens with prefabricated fracture spacing $\geq 300 \mathrm{~mm}$. When $\sigma 0 \mathrm{n}=2 \mathrm{MPa}$, cracks penetrate through the mid-layer of specimens with prefabricated fracture spacing $\geq 240 \mathrm{~mm}$. Cracks penetrate through the mid-layer of specimens with prefabricated fracture spacing $\geq 180 \mathrm{~mm}$ at $\sigma 0 \mathrm{n}=4 \mathrm{MPa}$. Cracks penetrate through the mid-layer of specimens with prefabricated fracture spacing $\geq 120 \mathrm{~mm}$ at $\sigma 0 \mathrm{n}=10 \mathrm{MPa}$. The bedding plane tensile strength in Fig. 18(f) is $\sigma 0 \mathrm{n}=17$ $\mathrm{MPa}$, and due to the strong bedding plane strength, the cracks penetrated directly through all layers in all specimens without crack deflection and propagation.

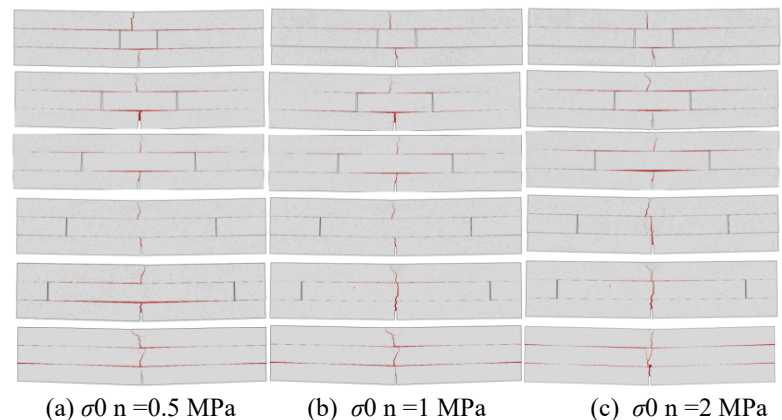

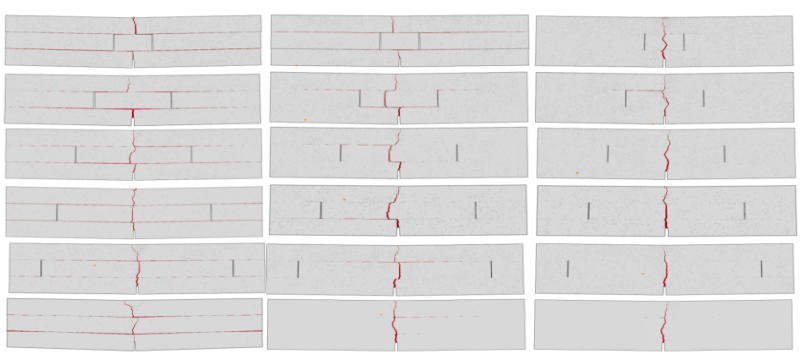

(d) $\sigma 0 \mathrm{n}=4 \mathrm{MPa}$

(e) $\sigma 0 \mathrm{n}=10 \mathrm{MPa}$

(f) $\sigma 0 \mathrm{n}=17 \mathrm{MPa}$

Comprehensive analysis of the above description on the crack propagation, the drawing curve is shown in Fig. 19. The specimen failure pattern was divided into two categories, namely crack coalescence and crack penetration. $\mathrm{P}_{0.5}, \mathrm{P}_{1.0}$, $\mathrm{P}_{2.0}, \mathrm{P}_{4.0}, \mathrm{P}_{10}$, and $\mathrm{P}_{17}$ respectively represent the six threshold values. $\mathrm{P}_{0.5}$ represents when the tensile strength reaches 0.5 $\mathrm{MPa}$ and the prefabricated fracture spacing is $\leq 300 \mathrm{~mm}$, cracks penetrate upwards around the prefabricated fracture. Cracks penetrate through the mid-layer when the prefabricated fracture spacing is $>300 \mathrm{~mm}$ until the crack penetrates and specimen damage occurs, and similarly for the others. It can be seen from Fig. 19, the rising section of each peak point are the specimen of crack penetration through the bedding plane. The falling and horizontal section are the specimen of crack penetration through the mid-layer. As the bedding plane strength increases, the maximum distance of the crack deflection on one side of the fracture spacing decreases. The fracture spacing tends to decrease, which indicates the smaller the fracture spacing, the easier it is for the crack to deflect from bypassing the mid-layer.

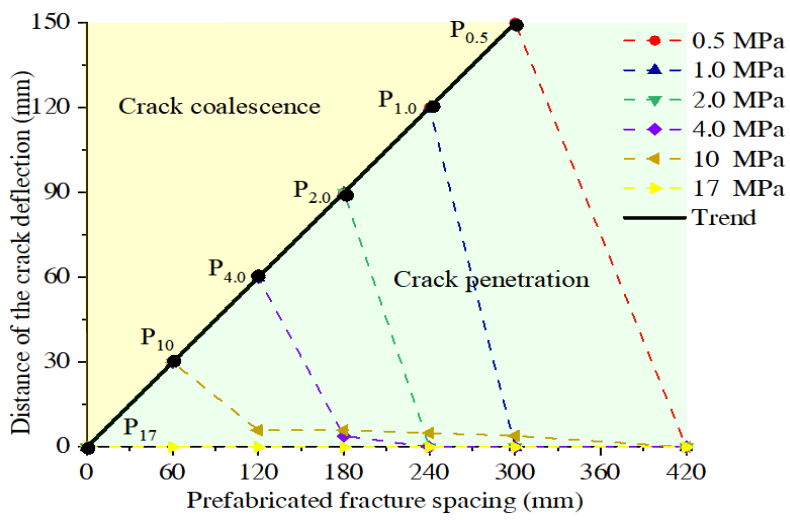

Fig. 19. Influence of prefabricated fracture spacing on crack evolution.

\section{Conclusions}

To study the crack propagation characteristics in the layered fractured rock mass, the layered fractured rock mass was prepared by using rock-like materials, the three-point bending test and numerical simulation were carried out. The main conclusions are as following:

(1) The crack propagation path is closely related to the bedding plane strength. When the bedding plane strength of the bedding plane is weak, the crack penetrates the mid-layer rock and propagates through the prefabricated fracture towards the upper rock layer, When the bedding plane strength is strong, the crack directly penetrates the mid-layer rock without deflecting along the bedding plane. When the bedding plane strength is at an moderate level, the crack undergoes a combined propagation mode with deflecting and penetrating at the bedding plane. 
Long Cheng, Xu Chang, Shuren Wang, Yunfei Wang and Minxia Zhang /

Journal of Engineering Science and Technology Review 14 (5) (2021) 90 - 99

(2) The load-displacement curves of the weaker and moderate bedding plane strength specimens show multiple peaks. AE events are more abundantly produced after the peak accompanied by crack deflection and penetration between the layers. The specimens with stronger bedding plane strength have a single peak load-displacement curve, showing brittle failure characteristics, and $\mathrm{AE}$ events are almost absent during the compression-density phase of the rock until near the peak load. The number of AE events also reaches a maximum when the load is rapidly decreasing.

(3) The spacing of the prefabricated fractures has an obvious influence on the fracture evolution. By varying the prefabricated fracture spacing, we can obtain that as the prefabricated fracture spacing increases, the cracks first penetrate upwards through the prefabricated fractures, and when the spacing exceeds a certain critical value, the main crack penetrates the mid-rock layer within the fracture spacing, and the critical value decreases as the bedding plane strength increases.

Since the layered rock mass in the earth's crust are not subjected to a single load, but to a combination of various complex loads under geological process, so, a more in-depth study on the failure phenomenon of the layered fractured rock masses under the combined loads is necessary.

\section{Acknowledgements}

This work was financially supported by the National Natural Science Foundation of China (51774112; 51674100), and the Fundamental Research Funds for the Universities of Henan Province (NSFRF200202), China.

This is an Open Access article distributed under the terms of the Creative Commons Attribution License.

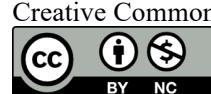

\section{References}

1. Sissins, S., Paraskevopoulou, C., "Assessing TBM performance in heterogeneous rock masses". Bulletin of Engineering Geology and the Environment. 80(8), 2021, pp. 6177-6203.

2. Wang, S. R., Li, N., Li, C. L., Zou, Z. S., Chang, X., "Instability mechanism analysis of pressure-arch in coal mining field under different seam dip angles". DYNA, 90(3), 2015, pp. 279-284.

3. Singh, P. K., Singh, K. K., Singh, T. N., "Slope failure in stratified rocks: a case from NE Himalaya". Landslides, 14(4), 2017, pp. 1319-1331.

4. Tang, H. M., Yong, R., Ez Eldin, M. A. M., "Stability analysis of stratified rock slopes with spatially variable strength parameters: the case of Qianjiangping landslide". Bulletin of Engineering Geology and the Environment, 76(3), 2017, pp. 839-853.

5. Paraskevopoulou, C., Skolidis, A., Parsons, S, Marinos, V., "Integrating uncertainty into geotechnical design of underground openings in tectonically undisturbed but lithologically varied sedimentary environments". Tunnelling and Underground Space Technology, 113, 2021, pp. 103979.

6. Garzon, S. E. R., "Analytical solution for assessing continuum buckling in sedimentary rock slopes based on the tangent-modulus theory". International journal of rock mechanics and mining sciences, 90, 2016, pp. 53-61.

7. Gross, M., Engelder, T., "Strain accommodated by brittle failure in adjacent units of the Monterey Formation, U.S.A.: scale effects and evidence for uniform displacement boundary conditions". Journal of Structural Geology, 17(9), 1995, pp. 1303-1318.

8. Ji, S. C., Saruwatari, K., "A revised model for the relationship between joint spacing and layer thickness". Journal of structural geology, 20(11), 1998, pp. 1495-1508.

9. Debecker, B., Vervoort, A., "Two-dimensional discrete element simulations of the fracture behaviour of slate". International Journal of Rock Mechanics and Mining Sciences, 61, 2013, pp. 161-170.

10. Hadei, M. R., Veiskarami, A., "An experimental investigation of hydraulic fracturing of stratified rocks". Bulletin of Engineering Geology and the Environment, 80(1), 2021, pp. 491-506.

11. Douma, L. A. N. R., Regelink, J. A., Bertotti, G., Boersma, G., Boersma, Q. D., Barnhoorn, A., "The mechanical contrast between layers controls fracture containment in layered rocks". Journal of Structural Geology, 127, 2019, pp. ID 103856.

12. Heng, S., Li, X, Liu, X., Yan, C., "Experimental study on the mechanical properties of bedding planes in shale". Journal of Natural Gas Science and Engineering, 76, 2020, pp. ID 103161.

13. Kim, J. W., Thompson, V. P., Rekow, E. D., Jung, Y. G., Zhang, Y. "Fracture modes in curved brittle layers subject to concentrated cyclic loading in liquid environments". Journal of Materials Research, 24(3), 2009, pp. 1075-1081.

14. Garagash, I. A., Osiptsov, A. A., "Fracture propagation in an initially stressed anisotropic reservoir under shear: Reorientation and fluid lag". Engineering Fracture Mechanics, 242, 2021, pp. ID 107457.
15. Chang, X., Deng, Y., Li , Z. H., Wang, S. R., Tang, C. A., "Crack propagation from a filled flaw in rocks considering the infill influences". Journal of Applied Geophysics, 152, 2018, pp. 137-149.

16. Wang, S. R., Xu, D. F., Hagan, P., Li, C. L., "Fracture characteristics analysis of double-layer rock plates with both ends fixed condition". Journal of Engineering Science and Technology Review, 7(2), 2014, pp. 60-65.

17. Chang, X., Zhao, H. B., Cheng, L., "Fracture propagation and coalescence at bedding plane in layered rocks". Journal of Structural Geology, 141, 2020, pp. ID 104213.

18. Zhao, Y. H.,, Wang, S. R., Zou, Z. S., Ge, L. L., Cui, F., "Instability characteristics of the cracked roof rock beam under shallow mining conditions". International Journal of Mining Science and Technology, 28(3), 2018, pp. 437-444.

19. Wang, S. R., Wu, X. G., Zhao, Y. H., Hagan, P., Cao, C., "Evolution characteristics of composite pressure-arch in thin bedrock of overlying strata during shallow coal mining". International Journal of Applied Mechanics,11(3), 2019, pp. ID 1950030.

20. Yang, S. Q., Yang, Z., Zhang, P. C., Tian, W. L., "Experiment and peridynamic simulation on cracking behavior of red sandstone containing a single non-straight fissure under uniaxial compression". Theoretical and Applied Fracture Mechanics, 108, 2020, pp. ID 102637.

21. Yang, S., Tian, W., Liu, X., Huang, Y. H., Yang, J., "An experimental study on failure mechanical behavior and cracking mechanism of rectangular solid sandstone containing two noncoplanar fissures under conventional triaxial compression". Theoretical and Applied Fracture Mechanics, 114, 2021, pp. 102975.

22. Zhao, Y. H., Wang, S. R., Zou, Y. F., Wang, X. C., Huang, B. Q., Zhang, X. G., "Pressure-arching characteristics of fractured strata structure during shallow horizontal coal mining". Tehnicki VjesnikTechnical Gazette, 25(5), 2018, pp. 1457-1466.

23. Luo, C., Yang, X. A., Wang, H., Ma, M. J., Gen, J. Y., "Experimental study on anchoring behavior of non-persistent jointed rock mass". Journal of Engineering Science and Technology Review, 13(2), 2020, pp. 30-38.

24. Lei, R., Zhang, Z., Berto, F., Ranjith, P. G., Zhang, C. P., "Strain localization and cracking behavior of sandstone with two gypsuminfilled parallel flawsv". Theoretical and Applied Fracture Mechanics, 112, 2021, pp. ID 102873.

25. Kazarinov, N. A., Petrov, Y. V., Cherkasov, A. V., "Instability effects of the dynamic crack propagation process". Engineering Fracture Mechanics, 242, 2021, pp. ID 107438.

26. Morgan, S. P., Einstein, H. H., "Cracking processes affected by bedding planes in Opalinus shale with flaw pairs". Engineering Fracture Mechanics, 176(1), 2017, pp. 213-234.

27. Ahmadi, M., Seyedin, S. H., Seyedin, S. V., "Investigation of the mechanical performance of fiber-modified ceramic composites using finite element method". Technical Journal, 13(3), 2019, pp. $173-17$ 